\title{
A Study of Polysemy of "Agent" Based on the Prototype Theory
}

\section{Pei Ding}

School of English Studies, Shanghai Industry \& Commerce Foreign Languages College, Shanghai, China

Email: dingpeih@gmail.com

How to cite this paper: Ding, P. (2021). A Study of Polysemy of "Agent" Based on the Prototype Theory. Open Journal of Social Sciences, 9, 441-447.

https://doi.org/10.4236/jss.2021.910030

Received: September 22, 2021

Accepted: October 26, 2021

Published: October 29, 2021

\begin{abstract}
Polysemy reflects the principle of economy of human language: to reduce the number of words thus releasing human's memory burden. It's not only a hot topic in L2 vocabulary teaching and learning, but also studied by cognitive linguists. In this article, polysemy is analyzed from the perspective of The Prototype Theory. The word "agent" is taken as an example since its meanings vary from chemical substance, to deputy in business, a deputy program in computer science, and so on. Besides, how these meanings are related is discussed. The analysis is intended to give some implications for the construction of a new definition model for English learners' dictionaries, as well as for how to teach and learn vocabulary more effectively.
\end{abstract}

\section{Keywords}

Agent, Polysemy, The Prototype Theory, Conceptual Metaphor

\section{Introduction}

"Polysemy" comes from Greek. The prefix "poly-" means multiple or many; -semy means meaning or implication (Su, 2020). Polysemy refers to the phenomenon that a word is entitled with more than one meaning, and often these meanings of this word are related to each other to some extent.

Over decades, word meaning has been researched and discussed by many linguists. The starting point of study on word meaning formation and development is categorization; category and categorization are among hot topics of cognitive linguistics. Jackendoff (1985) pointed out that categorization is the outcome of the juxtaposition of two conceptual structures; Ungerer \& Schmid (1996) thought that categorization is the mental process of classification; according to Driven \& Verspoor (1998), categorization is the ability to perceive different 
things as examples of the same category. After the process of categorization, category is stored in human's mind as concept, then meaning is formed, which some scholars call "mental lexicon". When the meaning or mental lexicon is entitled with some linguistic form, it's represented by language symbols. As long as humans have language, category, concept and meaning can't be formed without words (Wang, 2006).

However, different opinions have been held about category and categorization, by two theory systems: the classical theory of categories and the theory of prototypes, or the prototype theory.

According to the classical theory of categories, category is a group of elements with common features. Furthermore, the feature is not graded but binary. An element is either a member or non-member; the boundary of the category is clear-cut (Wang, 2006). In the 1950s and 1960s, semantic structuralists put forward component analysis (CA) to analyze the meaning of word. The theoretical foundation of this method is that word meaning can be decomposed into smaller meaning components, i.e. semantic feature. In component analysis of semantics, plus $(+)$ or minus $(-)$ is used to indicate whether some semantic feature is included in the meaning of a word. Semantic feature symbols are usually capitalized. For example, the word man can be marked as [+HUMAN] [+ADULT] [+ANIMATE] and [+MALE]. Similarly, the word woman can be expressed as [+HUMAN] [+ADULT] [+ANIMATE] and [+FEMALE] (Dai \& He, 2013). The advantage of component analysis is that it provides a new method of discussing and analyzing word meaning and the relations among them. However, this method doesn't explain how the meanings are related or the meaning extension mechanism of polysemy.

According to embodied philosophy, traditional categorization theory is only based on a priori speculation, not the result of empirical research. In the 1950s, through a study on "game", Wittgenstein discussed and analyzed the uncertainty of category's boundary, the difference between central member and edge member, and put forward the famous family resemblances (Wittgensein, 1978; Chapman \& Dixon, 1987; Wang, 2006). After Wittgenstein, the theory of prototypes is developed.

The differences between the classical category theory and modern category theory can be summarized as follows: According to the former, category is objective, the category members depend on a group of sufficient and necessary condition, and category boundary is definite; according to the later, category correlates with experience, the status of category members are different, and the category boundary is indefinite. Through comparing the two category theories, we can see clearly that the modern category theory is closer to our cognition, and more scientific and explainable; and has been widely applied in both verbal and nonverbal areas. However, they are complementary in some aspect and both are used in the process of categorization in our life (Rosch \& Lloyd, 1978; Coleman et al., 1981; Lakoff, 1987; Taylor, 2001). 
The appearance of cognitive linguistics provides a new perspective for the research on word meaning and polysemy. According to the prototype theory in cognitive linguistics, the meanings of a word are a prototype category. Every word has its basic meaning and extended meaning. Polysemy is the result of human's cognitive categorization and conceptualization, and of the extension process from basic meaning to extended meaning. Polysemous category is a structure of extension based on the meaning of prototype.

In the cognition theory frame, prototype, family similarity, stigma, metaphor and metonymy are all closely related with polysemy. The extended meaning diverged from the core meaning together makes a semantic network. The core meaning has a stigma in human's mind and forms conceptual metaphor. In the process, new meanings are accepted. Conceptual metaphor impels the variation of vocabulary and provides us with a key to understanding polysemy.

In this article, the prototype theory is discussed mainly by the example of "agent", including what the central meaning is, how its meanings are extended and how the meanings are related to each other. The use of corpus research is combined with qualitative method. In the end, a new definition model for English learners' dictionaries is put forward, in order to improve the efficiency of L2 vocabulary learning.

\section{Research Design}

In this article, "agent" is searched in Corpus of Contemporary American English (COCA). And then we made a research on 4 dictionaries. Therefore, quantitative and qualitative methods are combined in this research.

\subsection{Research Questions}

1) What's the central meaning of agent and what are the extended meanings?

2) How are the different meanings related to each other?

3) What implications can we get for dictionary editing and for L2 vocabulary learning?

\subsection{Research Tools}

1) Corpus. The author chose Corpus of Contemporary American English (COCA) as the database, searched "agent" and selected randomly 77 items to analyze.

2) Dictionaries. Dictionary is an indispensable tool in language acquisition. The article researched the meanings of agent in 4 dictionaries: Longman Dictionary of Contemporary English, Shoter Oxford English Dictionary, Cobuild English-Chinese Dictionary and Concise Oxford English-Chinese Dictionary.

\section{Data Collection and Analysis}

The word agent is composed of two parts: ag- and sent. Ag- means to act or to do; ent means people. Therefore, agent means "one who acts". We will make a 
research on meanings of "agent" in the Corpus of Contemporary American English (COCA), to verify the contemporary meanings of agent.

\subsection{Corpus Analysis}

We made a search of "agent" on COCA, randomly selected 77 items and categorized them into the following domains:

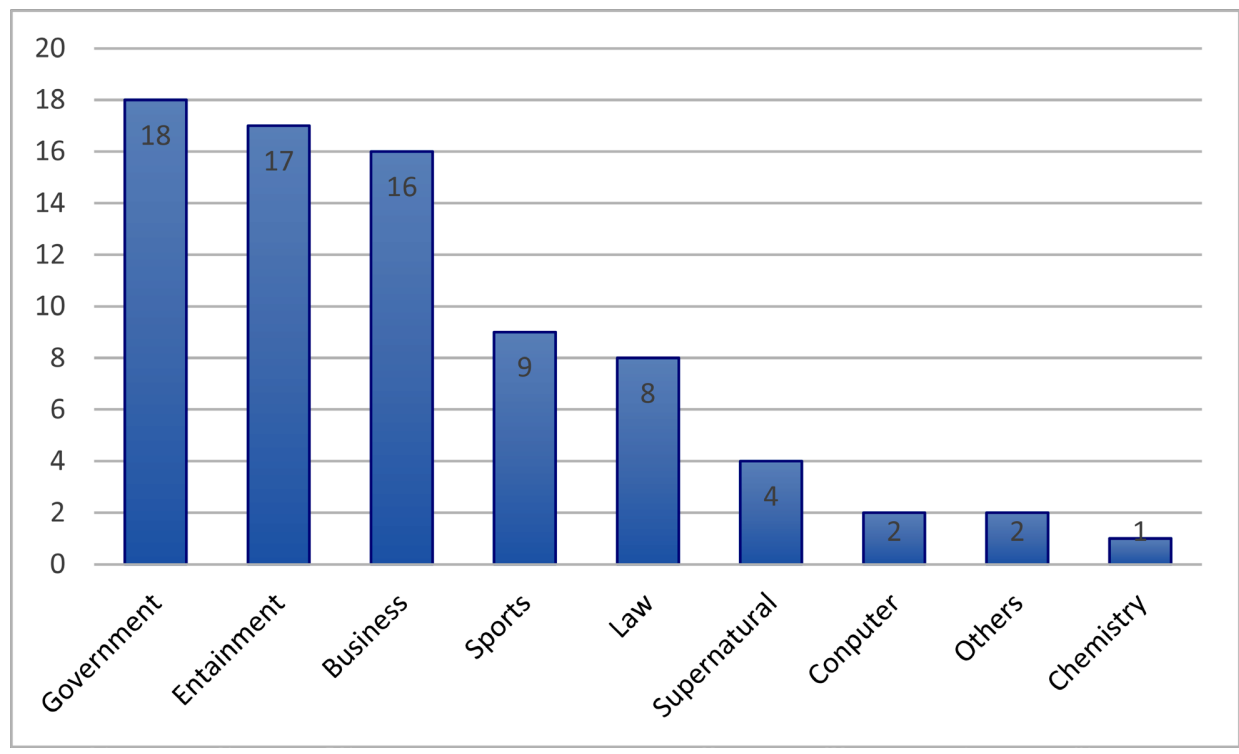

(Note: others mainly refer to people who act or bring news representative of others.)

Chart 1. "Agent” from COCA.

From Chart 1, we can see that government, entertainment, business, sports, law, religion and others all refer to people who act or work for others. Therefore, we make a further category of the meanings of "agent":

Table 1. Category of meanings of "agent”.

\begin{tabular}{|c|c|c|}
\hline Meaning & Field & Explanations or Examples \\
\hline \multirow{8}{*}{$\begin{array}{l}\text { A representative who acts on } \\
\text { behalf of other persons or } \\
\text { organizations }\end{array}$} & Government & $\begin{array}{l}\text { e.g. The agent spied for East Germany for more than twenty years. } \\
\text { e.g. The Attorney General plans to meet with FBI agents and civil rights investigators. }\end{array}$ \\
\hline & Entertainment & $\begin{array}{l}\text { e.g. Top theatrical agents are beating a path to the teenager's door. } \\
\text { e.g. He's busy touting his client's latest book around London's literary agents. }\end{array}$ \\
\hline & Business & e.g. Our agent in Rome deals with all our Italian business. \\
\hline & Sports & $\begin{array}{l}\text { e.g. Therefore, in the face of this urgent need regulating sports agent market, we must propose } \\
\text { appropriate countermeasures to strengthen management. }\end{array}$ \\
\hline & Law & $\begin{array}{l}\text { e.g. The spouse or children of a judge may not be the law agent or defender in the cases handled } \\
\text { by the court that judge belongs to. }\end{array}$ \\
\hline & Supernatural & $\begin{array}{l}\text { e.g. "Whether it's a dead ancestor or God, whatever supernatural agent it is, if you think they're } \\
\text { watching you, your behavior is going to be affected," he says. }\end{array}$ \\
\hline & Linguistics & $\begin{array}{l}\text { Agent (grammar), the participant of a situation that carries out the action in this situation; also } \\
\text { the name of the thematic role (also known as the thematic relation) }\end{array}$ \\
\hline & & $\begin{array}{l}\text { Agent noun (or nomen agentis), word that is derived from another word denoting an action, and } \\
\text { that identifies an entity that does that action }\end{array}$ \\
\hline
\end{tabular}




\section{Continued}

A substance that exerts some Medical science A chemical or a substance that produces an effect or a change or is used for a particular purpose. force or effect. e.g. Alkyl indicant is a new non-ionic surface active agent.

Computer Agent means a deputy program independent of an application program.

Agent architecture, blueprint for software agents and intelligent control systems, depicting the arrangement of components Agent-based model, computational model for simulating the actions and interactions of autonomous individuals with a view to assessing their effects on the system as a whole Intelligent agent, autonomous entity which observes and acts upon an environment and directs its activity towards achieving goals

Software agent, piece of software that acts for a user or other program in a relationship of agency User agent, the client application used with a particular network protocol

active and efficient cause $\quad$ - $\quad$ e.g. Agent of change

From Table 1, we can see that the central meaning of agent is someone who acts or do for others. It's a person whose job is to act for, or manage the affairs of, other people in business, politics, etc. a person whose job is to arrange work for an actor, musician, sports player etc. or to find sb who will publish a writer's work. Then it extends to the substance or program that can exert some force of effect. And it further extends to abstract meaning: an active and efficient cause.

The analysis above shows that in the semantics network of agent, the first one is the central meaning, and then produces other extended meanings through metaphor and metonymy. The semantics network is constructed around the central meaning.

\subsection{Dictionary Explanations Analysis}

The word "agent" is looked up in the following four dictionaries:

Comparing the explanations in Table 2 with the results of corpus analysis, we can see some problems in the editing of dictionaries:

Table 2. "Agent" from dictionaries.

\begin{tabular}{|c|c|c|}
\hline Type & Dictionary & Explanations \\
\hline \multirow[t]{2}{*}{ English-English } & $\begin{array}{l}\text { Longman Dictionary of } \\
\text { Contemporary English }\end{array}$ & $\begin{array}{l}\text { 1. A person or company that represents another person or company, especially in business; } 2 \text {. } \\
\text { someone who finds work for actors, musicians etc, or who finds someone to PUBLISH a writers' } \\
\text { work; } 3 \text {. someone who works for a government or police department, especially in order to get } \\
\text { secret information about another country or organization; } 4 \text {. technical a chemical or substance } \\
\text { that is used for a particular purpose or that has a particular effect; } 5 \text {. someone or something that } \\
\text { affects or changes a situation. }\end{array}$ \\
\hline & $\begin{array}{l}\text { Shoter Oxford English } \\
\text { Dictionary }\end{array}$ & $\begin{array}{l}\text { 1. A person who or thing which produces an effect; (the cause of) a natural force or effect on } \\
\text { matter; } 2 \text {. A person who acts for another in business, politics, etc.; } 3 \text {. The material cause or } \\
\text { instrument; } 4 \text {. A person who or thing which acts or exerts power spec in GRAMMAR, the entity } \\
\text { performing the action of the verb Opp. patient or instrument. }\end{array}$ \\
\hline English-Chinese & $\begin{array}{l}\text { Cobuild English-Chinese } \\
\text { Dictionary }\end{array}$ & $\begin{array}{l}\text { An agent is } 1.1 \text { someone who you pay to do business or look after your affairs on your behalf. 代 } \\
\text { 理人; 代表. } 1.2 \text { someone who arranges work for actors, musicians, etc., in return for a fee. 演员, } \\
\text { 音乐家等的)经纪人. } 1.3 \text { a person or company who represents a government, organization, or } \\
\text { another company in a particular place. 代理商; 公司代表; 政府代表. } 1.4 \text { someone who works } \\
\text { for a country's secret service. 间谍; 特务; 情报员. } 1.5 \text { a person, power, or force which has a } \\
\text { particular effect or influence, or which is the means or cause of something happening. 动力; 因 } \\
\text { 素; 媒介; 工具 } 1.6 \text { a chemical or substance which causes a change in other chemicals or } \\
\text { substances which it is in contact with. 剂; 作用剂 }\end{array}$ \\
\hline
\end{tabular}




\section{Continued}

Concise Oxford 1. a person that provides a particular service, typically one organizing transactions between two

English-Chinese Dictionary other parties 代理人,代理商; a person who manages financial or contractual matters for a performer, writer or sportsperson 经纪人 2. a person who works in secret to obtain information for a government 特工, 间谍 3. a person or thing that takes an active role or produces a specified effect 动原, 能因, 使然力> Grammar: the doer of an action 施事 4. Computing: an independently operating Internet program, typically one that performs background tasks such as information retrieval or processing on behalf of a user or other program 代理程序 DERIVATIVES 派生词 agentive adj (Grammar<语法>) ORIGIN 词源 ME: from L. agent-, agere 'to do

1) The meanings are not complete in the dictionaries. For example, in the Longman Dictionary of Contemporary English and Longman Dictionary of Contemporary English, the terms in computer science are missing. Therefore, English learners can't use the word eligibly, since usually only one or two of the meanings are listed in dictionaries or taught in class.

2) The meanings in the dictionaries all seem to be parallel and independent, while in fact some are central meanings and some are extended meanings. For example, in the Cobuild English-Chinese Dictionary and Concise Oxford English-Chinese Dictionary, all the meanings are listed in a linear sequence. However, it's worth mentioning that when translated into Chinese, all the meanings seem completely unrelated, especially with the totally different characters. It's the same word in English, while it takes efforts to connect the meanings in Chinese. This results in the problem that Chinese English learners can't see the relations among the meanings of the same word and they will be confused over why the word can be used in so many different fields. The difficulty in making cognitive connections among the different meanings of a polysemy causes great trouble in vocabulary learning.

According to the analysis above, in vocabulary teaching, teachers should elaborate how diverse meanings are extended through cognitive mechanism such as metaphor and metonymy and ask students to notice the essential relations among the meanings. More importantly, as the most significant tool of vocabulary learning, a dictionary should indicate the cognitive model of word meaning. Therefore, a new definition model (seen in Table 3) for English learners' dictionaries is proposed as follows:

Table 3. A new model for English learners' dictionaries.

\begin{tabular}{ccc}
\hline Original meaning & Field or context & Example \\
\hline A & A1 \\
& A2 \\
B & B1 \\
& B2 \\
C & C1 \\
& C2 \\
\hline
\end{tabular}


In the model, A, B and C are general meanings of the word. A represents the central meaning of the word, and it indicates the source or origin. $\mathrm{B}$ and $\mathrm{C}$ are listed in the developing sequence and indicate the cognitive extension of the word meaning. The second column lists the domains or fields that the word can be used. In the third column are examples that are extracted from corpus. In this way, the users will clearly see the relations of the different meanings of a word and would soon recognize their relative meanings in different contexts.

\section{Conclusion}

This article takes an example of the word "agent", to discuss the meanings' relations of a polysemy, from the perspective of cognitive linguistics, especially based on the Prototype Theory. It's found that the semantic network of a polysemy is constructed around the prototype meaning. Multiple meanings are extended through metaphor or metonymy. This study gives some implications for L2 vocabulary learning and is beneficial for students to understand and memorize words, thus improving their word learning efficiency. However, further research is still needed to analyze more words, to elaborate how to implement the cognitive approach in L2 vocabulary teaching, and to improve the new definition model of dictionary editing.

\section{Conflicts of Interest}

The author declares no conflicts of interest regarding the publication of this paper.

\section{References}

Chapman, M., \& Dixon, R. (1987). Meaning and the Growth of Understanding: Wittgenstein's Significance for Development Psychology (pp. 151-166). Springer. https://doi.org/10.1007/978-3-642-83023-5

Coleman, L., \& Paul, K. (1981). Prototype Semantics: The English Word LIE. Language, 57, 26-44. https://doi.org/10.1353/lan.1981.0002

Dai, W. D., \& He, Z. X. (2013). A New Concise Course on Linguistics for Students of English. Shanghai Foreign Language Education Press.

Driven, R., \& Verspoor, M. (1998). Cognitive Exploration of Language and Linguistics. John Benjamins. https://doi.org/10.1075/clip.1(1999)

Jackendoff, R. S. (1985). Semantics and Cognition. MIT Press.

Lakoff, G. (1987). Women, Fire and Dangerous Things: What Categories Reveal about the Mind. The University of Chicago Press. https://doi.org/10.7208/chicago/9780226471013.001.0001

Rosch, E., \& Lloyd, B. (1978). Cognition and Categorization. Lawrence Erlbaum.

Su, L. Q. (2020). A Cognitive Study on Polysemy of “Table”. English Square.

Taylor, L. R. (2001). Linguistic Categorization: Prototypes in Linguistic Theory. Foreign Language Teaching and Research Press.

Ungerer, F., \& Schmid, H. J. (1996). An Introduction to Cognitive Linguistics. Longman. Wang, Y. (2006). Cognitive Linguistics. Shanghai Foreign Language Education Press.

Wittgensein, L. (1978). Philosophical Investigation. Basil Blackwell. 